\title{
Clubfoot Treatment
}

\section{Ponseti and French Functional Methods are Equally Effective}

\author{
Shawne Faulks RN, MSN, CNS, B. Stephens Richards MD
}

Published online: 26 February 2009

(C) The Association of Bone and Joint Surgeons 2009

\begin{abstract}
Over the past 15 years, the reemergence of nonoperative treatment of clubfeet throughout the world has been profound. Two methods have been utilized - the Ponseti method and, to a lesser extent, the French functional method. Our review presents one institution's experience using both methods. Satisfactory initial correction was achieved in $95 \%$ of idiopathic clubfeet, regardless of method. However, maintenance of the correction was challenging as relapses occurred in $37 \%$ of feet treated by the Ponseti method and $29 \%$ of feet treated by the French functional method. At an average 4.3 year followup, using either method, posteromedial releases were avoided in $84 \%$ of our patients. Using gait analysis to evaluate the function of children treated with these techniques, there was no difference in cadence parameters between the two groups. More of the children treated with the French method walked with knee hyperextension, a mild equinus gait, and mild footdrop. In contrast, more of the patients in the Ponseti group demonstrated mildly increased stance-phase dorsiflexion and a calcaneus gait.

Level of Evidence: Level V, therapeutic study. See the Guidelines for Authors for a complete description of levels of evidence.
\end{abstract}

\footnotetext{
Each author certifies that he or she has no commercial associations (e.g., consultancies, stockownership, equity interest, patent/licensing arrangements, etc.) that might pose a conflict of interest in connection with the submitted article.

Each author certifies that his/her institution has approved the reporting of these cases, that all investigations were conducted in conformity with ethical principles of research, and that informed consent for participation in the study was obtained.
}

S. Faulks, B. S. Richards $(\bowtie)$

Department of Orthopaedics, Texas Scottish Rite Hospital for Children, 2222 Welborn Street, Dallas, TX 75219, USA

e-mail: steve.richards@tsrh.org; cindy.daniel@tsrh.org

\section{Introduction}

Clubfoot is one of the most common pediatric orthopaedic conditions requiring comprehensive treatment [8]. Before the mid 1990s, surgery was the treatment of choice by most orthopaedic surgeons throughout North America. During that time, at Texas Scottish Rite Hospital for Children (TSRH), nearly $85 \%$ of the patients initially treated nonoperatively with below-knee serial casting for clubfoot underwent comprehensive releases. While extensive release of the clubfoot was thought to ensure full and lasting correction of the deformity, a functional outcome study performed at our institution revealed limitations from this approach occurred over time [10]. Patients who had undergone operative correction of their clubfeet, had reached the age of 10 years, and were considered to have a satisfactory clinical outcome (by the surgeon, patient, and family) had stiffness, weakness, residual intoeing, and disturbed knee kinematics. In the latter 1990s, the medical staff at TSRH, like so many pediatric orthopaedists across North America, emphasized nonoperative treatment of the clubfoot, using the French functional method since 1996 and the Ponseti casting method since 1999.

The French functional method for the nonoperative treatment of clubfoot originated in the 1970s with Masse, with further refinement and development of the technique throughout various French treatment centers during the next several decades $[1,2,5,12]$. The treatment method was brought to the United States (to TSRH) in 1996 by Alain Dimèglio, MD, and Frederique Bonnet, PT [15]. The method involves daily gentle mobilization and stretching of contracted tissues, stimulation and strengthening of weakened muscles, and taping and splinting to maintain the correction. All of this is performed by 
physical therapists experienced in the method. Most of the correction is obtained within the first 3 months of treatment, with full correction expected within 5 months. Parents are taught the technique, with home therapy continued until walking age. A below-the-knee Aquaplast splint (Patterson Medical, Bolingbrook, Illinois) is continued until 2 or 3 years of age in an effort to prevent recurrence of the deformity [15].

Professor Ignacio Ponseti developed guidelines for his method of nonoperative treatment in the 1940s, and this effective method remains essentially unchanged to this day. The TSRH orthopaedic staff received formal training from Dr. Ponseti during visits to Iowa in 1999 and 2000 and began utilizing his casting method at our institution. The method involves weekly gentle stretching and manipulation of the misaligned bones followed by application of a well-molded long-leg plaster cast. Frequently, a percutaneous tendoachilles lengthening (TAL) is performed to allow complete correction of the equinus deformity prior to the final cast (which is worn for 3 weeks). Correction of the deformity is usually obtained within 6 to 8 weeks and is maintained by full-time wear of the foot abduction brace for 3 months and part-time night and nap wear for approximately 2 to 3 years [14$16]$.

The purpose of our review is to summarize the previously reported TSRH experience of nonoperative clubfoot treatment using both the Ponseti method and the French functional method, to compare their clinical and functional effectiveness with each other, and to discuss lessons learned from the use of these treatment modalities. Some of our recently published information will be briefly summarized.

\section{Review}

In February 2001 we began a prospective, nonrandomized study in which all patients under 12 months of age with clubfeet were treated by either the Ponseti method or the French functional method. All patients we treated were enrolled except for those who had previous clubfoot surgery, who were excluded. Due to time and travel considerations involved with the French functional method, which requires daily visits, randomization of our patients was not possible and therefore parent selection of the treatment method was allowed after a thorough explanation of both methods. Pretreatment severity was scored using system of Dimèglio et al. and later outcome comparisons similarly scored [4]. Treatment was performed by seven orthopaedic surgeons or through the physical therapy department.
Idiopathic Clubfeet

I. Patients under 3 months of age who had no previous treatment

In a recently published Level II study, we reported 176 patients (267 feet) treated by the Ponseti casting method and 80 patients ( 119 feet) treated by the French functional method [18]. There was no difference in initial foot severity between treatment groups (average initial severity score: Ponseti group 12.1, French functional group 12.8). A satisfactory initial correction was achieved in $94.4 \%$ of the Ponseti group and $95 \%$ of the French functional group. This is consistent with other reports in the literature $[9,11$, 13]. However, maintenance of the correction proved challenging in our patient population. Relapses, in which there was a return of unacceptable hindfoot equinus and/or hindfoot varus, occurred in $37 \%$ of the feet treated by the Ponseti method that had satisfactory initial correction. Onethird of these relapsed feet were salvaged with further nonoperative treatment, but the remainder had surgery. Relapses occurred in $29 \%$ of the feet treated by the French method that had achieved initial correction. All of these had surgery. The clinical outcomes of these 386 feet were assessed after a minimum two-year followup. Outcomes for these nonoperative treatment methods were defined as good (plantigrade foot with or without a TAL), fair (plantigrade foot achieved only after a limited posterior release $[\mathrm{PR}]$, and/or an anterior tibialis tendon transfer [ATT], and/or lateral column shortening), or poor (plantigrade foot achieved only after a complete posteromedial release [PMR]). At an average followup of 4.3 years, the outcomes for the group treated by the Ponseti method were good for $72 \%$, fair for $12 \%$, and poor for $16 \%$. Outcomes for the group treated by the French method were good for $67 \%$, fair for $17 \%$, and poor for $16 \%$ (Table 1 ). We observed no differences $(\mathrm{p}=0.31)$ with use of the two methods over this short followup.

Table 1. Overall outcomes of the Ponseti casting and French functional methods

\begin{tabular}{|c|c|c|c|}
\hline \multicolumn{4}{|l|}{ Treatment method } \\
\hline \multicolumn{4}{|c|}{ Total outcomes ( $>2$-year followup) } \\
\hline & Good & Fair & Poor \\
\hline $\begin{array}{l}\text { Ponseti } \\
\quad(\mathrm{n}=267 \text { feet/ } \\
176 \text { patients })\end{array}$ & 193 feet $(72 \%)$ & 32 feet $(12 \%)$ & 42 feet $(16 \%)$ \\
\hline $\begin{array}{l}\text { PT } \\
\quad(\mathrm{n}=119 \text { feet } / \\
80 \text { patients })\end{array}$ & 80 feet $(67 \%)$ & 20 feet $(17 \%)$ & 19 feet $(16 \%)$ \\
\hline
\end{tabular}


II. Patients 3-12 months of age who received previous nonoperative treatment elsewhere

Prior to learning the French functional method and Ponseti casting method at our institution, most of the older infants (3-12 months of age) who presented with deformity and those who had failed treatment at other institutions were scheduled for surgery. After gaining experience with these nonoperative techniques, it became increasingly apparent that many patients who presented after 3 months of age could indeed obtain correction with nonoperative treatment. In 45 previously treated clubfeet that underwent repeat nonoperative treatment at our institution, good outcomes were achieved in $31(70 \%)$. For the remaining 14 feet that needed surgery, $43 \%$ had never achieved sufficient initial correction and $57 \%$ had recurrence of the deformity. Followup on these patients averaged 4.3 years. We found better outcomes with the Ponseti method. We believe the lack of routine TALs in the French functional group resulted in the need for more posterior releases.

III. Gait analysis comparison between treatment methods

A gait analysis study on 105 TSRH patients (with 154 involved feet) evaluated the function of children treated with these techniques [6]. Fifty-six of the patients were treated with Ponseti casts and 49 were treated with the French functional method. Seventy-nine of the feet were treated with casts and 75 treated with physical therapy. The patients had been treated between February 1998 and May 2004. Their age averaged 2.3 years. Temporal and kinematic data were classified as abnormal if they were more than one standard deviation from normal. We observed no differences in cadence parameters between the two groups. The rate of normal kinematic ankle motion in the sagittal plane was substantially higher in the group treated with physical therapy (65\% of the feet) than it was in the group treated with the Ponseti method (47\%). More of the children treated with the French method walked with knee hyperextension (37\% of the feet), a mild equinus gait (15\%), and mild footdrop (19\%); only one patient treated with the Ponseti method walked with an equinus gait, and only three demonstrated footdrop. In contrast, more of the patients in the Ponseti group demonstrated mildly increased stance-phase dorsiflexion (48\% of the feet) and a calcaneus gait (10\%). More feet in the physical therapy group had an increased internal foot progression angle (44\% compared with $24 \%$ in the Ponseti group). The rates of calcaneus gait and equinus gait were $\leq 15 \%$ in each nonoperative group. The differences between the two groups may, in part, be the result of the percutaneous Achilles tendon lengthening that is frequently performed as part of the Ponseti cast technique but less frequently in the French functional method.
IV. Patients who were later found to have developmental delays

Over time, we have found that a number of patients who initially were presumed to have idiopathic clubfeet have been noted to have delays in their development. We performed developmental assessments as part of the routine orthopaedic exam and a child was classified as delayed if they walked after 18 months of age. To determine the incidence of developmental delays, we reviewed 143 consecutive patients (222 feet) initially believed to have idiopathic clubfeet, with a minimum of 2 years followup. These 143 patients represent a portion of our prospective nonrandomized study that was begun in February 2001. Twelve of these 143 (8.4\%) patients were subsequently found to be delayed in their development. This incidence is higher than the national prevalence of global developmental delay, which is reportedly between $1 \%$ and $3 \%$ of the population [19]. Eight of the 12 delayed patients did not have an identifiable risk factor for the delay (born $>38$ weeks gestation, birth weight $>5$ pounds, did not require ventilator support). The feet in the delayed group were more severe initially (average initial score, 15.7) than those in the normal development idiopathic group (average initial score, 12.7). However, early clinical results were similar in both groups. Frequent developmental assessments will identify patients with clubfeet who are delayed and will optimize referral for appropriate evaluation and treatment.

\section{Nonidiopathic Clubfeet}

In general, our experience had been that clubfeet that were found in patients having other abnormalities did not respond well to nonoperative interventions, with most having extensive surgical releases to obtain plantigrade feet. After learning of these two nonoperative methods, we treated 45 patients (77 clubfeet) with a variety of diagnoses, including Down's syndrome, arthrogryposis, developmental delay and hypotonia, cerebral palsy, amniotic bands, VATER, tethered cord, and Larsen's syndrome. These patients represent a subset from our prospective nonrandomized study that was begun in February 2001. Treatment outcomes in this patient group have been good in $48 \%$, fair in $26 \%$, and poor in $26 \%$ of feet, regardless of which method was used. While there are still many clubfeet in this group of patients that will require surgery, nonoperative treatment has made a major impact by reducing the amount of surgery required to obtain plantigrade feet. This finding has also been reported by others $[3,7]$. 


\section{Discussion}

Specialized training of the physical therapist and committed, educated parents are crucial factors for the success of the French functional method of nonoperative treatment of clubfoot. Although the orthopaedist is not directly involved with the treatment in this method, he does assess the feet every 4-6 weeks to determine if sufficient improvement is being achieved. With greater experience on the part of the physical therapists come better results for patients. In 2005, we reported our early experience with patients treated with the French functional method. Forty-nine percent of the patients who were followed for a minimum of 20 months underwent either a posterior release or a posteromedial release [17]. Our most recent results demonstrate an improvement in outcomes, with $33 \%$ of the patients undergoing either a posterior release $(17 \%)$ or a posteromedial release $(16 \%)$ [18].

Until 2006, in an effort to preserve the strength of the gastrosoleus complex, TALs were avoided in patients treated with the French functional method. In our recent report, 32\% (38/119 feet) of the French PT feet underwent a TAL [18]. However, $63 \%$ of these 38 feet did not receive the TAL until 4 months of treatment had been administered. With a trend toward a higher incidence of posterior releases being necessary in the French functional group (17\%) when compared to the Ponseti casting group (12\%), we are now performing early TALs more routinely within the first three months of treatment in our French PT group. Although it is difficult to precisely quantify the amount of heelcord tightness that requires a TAL, we currently believe TAL is necessary if $25^{\circ}$ of dorsiflexion is not achieved [6]. Our belief is that this change in treatment protocol will, in the future, lessen the number of posterior releases that are needed in the French PT group.

In the past, Dimèglio advocated the use of a continuous passive motion machine (CPM) as part of the French functional method to allow further mobilization of the child's foot while sleeping [5]. He reported this reduced the incidence of extensive releases. At TSRH, CPM was utilized from 2000 to 2003. It was used at home during the first 12 weeks of treatment. Although our early experience suggested the CPM benefited patients with clubfeet which were rated "moderate" [17], over time its use showed no sustained benefit in the clinical outcomes between patients who used it and those who did not. As a result, CPM was discontinued in 2003.

As we discovered with the French method, greater experience with the Ponseti method leads to better outcomes. During our early experience with the Ponseti method, most of the feet that underwent a PMR had failed to achieve satisfactory initial correction. Some of the feet had been placed into braces prior to sufficient correction being obtained. Some patients' caregivers failed to return with the patient for the weekly cast changes, thus abandoning the treatment program. With a gain in experience, improvements in short-term outcomes were seen. It is clear that complete deformity correction must be achieved prior to brace application. If problems are encountered with tolerating brace wear after casting, a change to the French method of taping the foot may "rescue" some of these feet from relapse, thus avoiding the need for surgical management.

The use of a foot abduction orthosis upon completion of Ponseti cast treatment, as outlined by Dr. Ponseti [16], is believed to be a vital component to the maintenance of nonoperative deformity correction. It maintains the necessary external rotation position of the feet. Our results, and others, suggested those patients who tolerate prescribed brace wear have a better outcome than those who do not $[13,18]$. In those settings where patients are unable to tolerate brace wear, parents often report that this is due to irritability of the infant or to a limitation in the child's movement. Some braced patients develop skin problems, including heel sores. In an effort to improve brace tolerance and compliance, and ultimately outcomes, we have made numerous brace adaptations over the past few years and have incorporated the following various preemptive strategies.

Brace use is discussed with families at their initial visit and subsequently at each visit thereafter. The families are called by a nurse coordinator 24 to 48 hours after brace wear begins to help identify skin or wear problems early. Families are provided contact information for the hospital so if there are questions or concerns about brace use they can reach a care provider anytime. After noting that most brace difficulties were occurring early in the postcast treatment, we have increased the frequency of followup appointments for our patients. Many of our patients are seen 1 week after brace application with all patients seen monthly during the first 3 months of full-time brace wear then every 3 months until 2 years of age.

Adaptations to our foot abduction (external rotation) orthoses have included the routine application of a heel counter to maintain foot position in the shoes, use of a softer leather shoe to decrease skin friction, decreased external rotation for those experiencing brace tolerance difficulties, and, perhaps most important, a detachable bar which allows for easy shoe application and brace use. Despite all our efforts there are still patients who do not tolerate a brace. In these patients we believe crossover to the French method for taping and splinting has been beneficial in maintaining correction in some patients who are unable to tolerate the shoes/brace. The experience gained at TSRH in the nonoperative treatment of clubfeet using the Ponseti method and the French functional method during 
the past 9 years has yielded dramatic improvements in the nonoperative outcomes for our patients. Having the unique opportunity to offer both treatment options, as well as combining the treatment methods when needed, has maximized the benefits for our patients.

\section{References}

1. Bensahel H, Guillaume A, Czukonyi Z, Desgrippes Y. Results of physical therapy for idiopathic clubfoot: a long-term follow-up study. J Ped Orthop. 1990;10:18-192.

2. Bensahel H, Guillaume A, Csukonyi Z, Themar-Noel C. The intimacy of clubfoot: the ways of functional treatment. $J$ Ped Orthop Part B. 1994;3:155-160.

3. Boehm S, Limpaphayom N, Alaee F, Sinclair MF, Dobbs MB. Early results of the Ponseti method for the treatment of clubfoot in distal arthrogryposis. J Bone Joint Surg Am. 2008;90:15011507.

4. Diméglio A, Bensahel H, Souchet P, Mazeau P, Bonnet F. Classification of clubfoot. J Ped Orthop. 1995;4:129-136.

5. Diméglio A, Bonnet F, Mazeau P, De Rosa V. Orthopaedic treatment and passive motion machine: consequences for the surgical treatment of clubfoot. J Ped Orthop B. 1996;5:173-180.

6. El-Hawary R, Karol LA, Jeans KA, Richards BS. Gait analysis in children treated for clubfeet with physical therapy or the Ponseti cast technique. J Bone Joint Surg Am. 2008;90:1508-1516.

7. Gurnett CA, Boehm S, Connolly A, Reimschisel T, Dobbs MB. Impact of congenital talipes equinovarus etiology on treatment outcomes. Dev Med Child Neurol. 2008;50:498-502.

8. Herring JA, ed. Congenital talipes equinovarus (clubfoot). In: Tachdjian's Pediatric Orthopaedics, Vol. 2. 3rd ed. Philadelphia, PA: W.B. Saunders Company; 2002:922-959.
9. Herzenberg JE, Radler C, Bor N. Ponseti versus traditional methods of casting for idiopathic clubfoot. J Ped Orthop. 2002;22:517-521.

10. Karol LA, Concha MC, Johnston CE. Gait analysis and muscle strength in children with surgically treated clubfeet. J Ped Orthop. 1997;17:6:790-795.

11. Lehman WB, Mohaideen A, Madan S, Scher DM, Van Bosse HJ, Iannacone M, Bazzi JS, Feldman DS. A method for the early evaluation of the Ponseti (Iowa) technique for the treatment of idiopathic clubfoot. J Ped Orthop B. 2003;12:133-140.

12. Masse P. Le traitement du pied bot par la methode "fonctionnelle." In: Cahier d'enseignement de la SOFCOT, vol. 3. Paris, France: Expansion Scientifique; 1977:51-56.

13. Morcuende JA, Weinstein SL, Dietz FR, Ponseti IV. Plaster cast treatment of clubfoot: the Ponseti method of manipulation and casting. J Ped Orthop B. 1994;3:161-167.

14. Morcuende JA, Dolan LA, Dietz FR, Ponseti IV. Radical reduction in the rate of extensive corrective surgery for clubfoot using the Ponseti method. Pediatrics. 2004;113:376-380.

15. Noonan KJ, Richards BS. Nonsurgical management of idiopathic clubfoot. J Amer Acad Orthop Surg. 2003;11:392-402.

16. Ponseti IV, ed. Congenital Clubfoot: Fundamentals of Treatment. Oxford, England: Oxford University Press, 1996.

17. Richards BS, Johnston CE, Wilson H. Non-operative clubfoot treatment using the French physical therapy method. J Ped Orthop. 2005;25:98-102.

18. Richards BS, Faulks S, Rathjen KE, Karol LA, Johnston CE, Jones SA. A comparison of two nonoperative methods of idiopathic clubfoot correction: The Ponseti Method and the French Functional (Physiotherapy) Method. J Bone Joint Surg Am. 2008;90:2313-2321.

19. Simpson GA, Colpe L, Greenspan S. Measuring functional developmental delay in infants and young children: prevalence rates from the NHIS-D. Paediatr Perinat Epidemiol. 2003;17: $68-80$. 